\title{
Seawi-a sea urchin piwi/argonaute family member is a component of MT-RNP complexes
}

\author{
ALEXIS J. RODRIGUEZ, ${ }^{1}$ SUSAN A. SEIPEL, ${ }^{1}$ DANIELLE R. HAMILL, ${ }^{2}$ DANIELE P. ROMANCINO, ${ }^{3}$ \\ MARTA DI CARLO, ${ }^{3}$ KATHY A. SUPRENANT, ${ }^{2}$ and EDWARD M. BONDER ${ }^{1}$ \\ ${ }^{1}$ Program in Cellular and Molecular Biodynamics, Department of Biological Sciences, Rutgers University, Newark, New Jersey 07102, USA \\ ${ }^{2}$ Department of Molecular Biosciences, University of Kansas Lawrence, Kansas 66045, USA \\ ${ }^{3}$ Istituto di Biomedicina ed Immunologia Molecolare "Alberto Monroy" CNR, 90146 Palermo, Italy
}

\begin{abstract}
The piwi/argonaute family of proteins is involved in key developmental processes such as stem cell maintenance and axis specification through molecular mechanisms that may involve RNA silencing. Here we report on the cloning and characterization of the sea urchin piwi/argonaute family member seawi. Seawi is a major component of microtubule-ribonucleoprotein (MT-RNP) complexes isolated from two different species of sea urchin, Strongylocentrotus purpuratus and Paracentrotus lividus. Seawi co-isolates with purified ribosomes, cosediments with $80 \mathrm{~S}$ ribosomes in sucrose density gradients, and binds microtubules. Seawi possesses the RNA binding motif common to piwi family members and binds $P$. lividus bep4 mRNA, a transcript that co-isolates with MT-RNP complexes and whose translation product has been shown to play a role in patterning the animal-vegetal axis. Indirect immunofluorescence studies localized seawi to the cortex of unfertilized eggs within granule-like particles, the mitotic spindle during cell division, and the small micromeres where its levels were enriched during the early cleavage stage. Lastly, we discuss how seawi, as a piwi/argonaute family member, may play a fundamentally important role in sea urchin animal-vegetal axis formation and stem cell maintenance.
\end{abstract}

Keywords: axis specification; piwi; argonaute; mRNA localization; microtubule; mRNP

\section{INTRODUCTION}

Spatial segregation of "morphogenic determinants" within oocytes and eggs plays a fundamentally important role in the specification of cell fate during early development (Wilson 1925; Davidson 1986). In many organisms, the cortex of unfertilized eggs/oocytes serves as a repository of spatiotemporal information by sequestering translationally repressed RNP complexes containing specific mRNAs and ribosomal components (Sardet et al. 2002). Biochemical and morphological studies indicate that segregation of localized mRNAs often involves assemblages of localized mRNAs, polysomes, and accessory proteins such as motors, adaptors, and/or RNA binding proteins that form granulelike ribonucleoprotein structures that colocalize with cytoskeletal elements (Barbarese et al. 1995; Pokrywka and Stephenson 1995; Knowles et al. 1996; Lipshitz and Smibert 2000).

Reprint requests to: E.M. Bonder, Department of Biological Sciences, Rutgers University, 101 Warren Street, 135 Smith Hall, Newark, NJ 07102, USA; e-mail: ebonder@andromeda.rutgers.edu; fax: (973) 353-1007.

Article and publication are at http://www.rnajournal.org/cgi/doi/10. 1261/rna.7198205.
Unfertilized sea urchin eggs possess a preexisting, maternally specified gradient of morphogen that sets the future orientation of the embryonic animal-vegetal axis (Runnstrom 1929). During early cleavage stages three distinct cell fate domains are established along the animalvegetal axis in the sea urchin embryo. Near the animal pole, orthologs of the transcription factors SoxB1, SoxB2, and Ets4 exhibit a nuclear localization pattern in cells destined to form ectoderm (Angerer and Angerer 2000). Near the vegetal pole, $\beta$-catenin is localized to the nuclei of cells destined to become coelomic and skeletogenic mesoderm (Logan et al. 1999). In the cells between these two regions both transcriptional systems are present, resulting in the production of mesodermal, endodermal, and ectodermal cell types (Angerer and Angerer 2000; Brandhorst and Klein 2002). During the early cleavage stage of sea urchin embryogenesis, these regulatory pathways are activated cell autonomously, suggesting that the molecular factors needed for early pattern development are maternally inherited.

In Strongylocentrotus purpuratus eggs and two-cell embryos, a reconstituted microtubule-ribonucleoprotein (MTRNP) complex consisting of ribosomes, microtubules, mRNA, $107-\mathrm{kDa}$ major vault protein, 77-kDa EMAP, 80- 
and $66-\mathrm{kDa}$ poly-A binding proteins, and an uncharacterized $100-\mathrm{kDa}$ protein was isolated by temperature- and $\mathrm{pH}$ dependent polymerization cycling of MTs in cell extracts (Suprenant et al. 1989; Hamill et al. 1994; Hamill and Suprenant 1997). By electron microscopy, the MT-RNP complexes consisted of microtubule arrays studded with ribosomes that appeared to be connected via a salt-extractable, protease-sensitive stalk (Hamill et al. 1994). Similar studding of ribosomes on MTs has been reported to occur in vivo along the MT arrays of the mitotic spindle (Hirokawa et al. 1985; Suprenant et al. 1989) and ciliary platform rootlets of epithelial cells at the primary mesenchyme blastula stage of sea urchin embryogenesis (Gibbins et al. 1969).

When isolated by phenol/chloroform extraction, the mRNA associated with the MT-RNP complex is translationally competent, yielding a specific set of polypeptides by in vitro translation (Hamill et al. 1994). When isolated MTRNP complexes were placed into the same in vitro translation system, the associated mRNAs failed to translate into protein (Hamill et al. 1994), suggesting the complex existed in a translationally arrested state. MT-RNP complexes isolated from the sea urchin Paracentrotus lividus contain bep4 mRNA. Bep4 mRNA is asymmetrically segregated in unfertilized eggs and embryos in a microtubule-dependent manner (Romancino et al. 1998; Romancino and DiCarlo 1999) and Bep4 protein is functionally linked to determination of the animal-vegetal axis (Romancino et al. 2001). The aforementioned are hallmark properties for a cellular component that functions in establishment and maintenance of the animal-vegetal axis during sea urchin development.

A

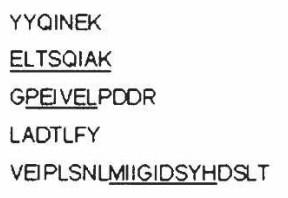

B

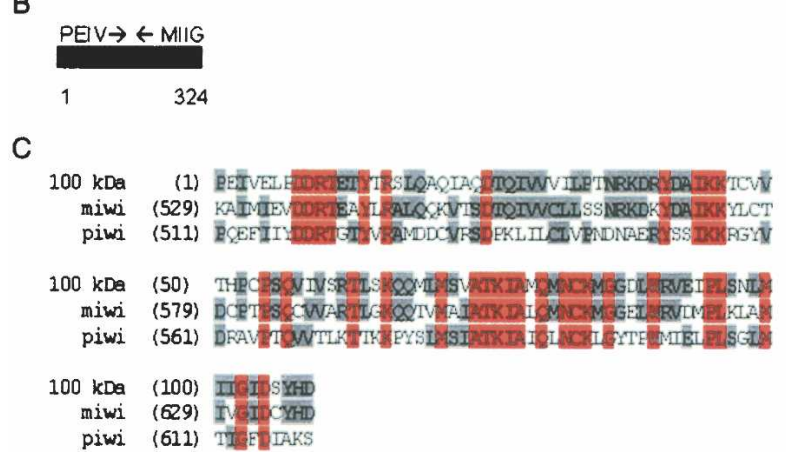

In this report, we characterize seawi-a sea urchin 100$\mathrm{kDa}$ member of the piwi/argonaute family of proteins. Seawi is a component of MT-RNP complexes possessing a subset of mRNA, including one (bep4) known to have a role in axis formation. Identification of seawi association with sea urchin MT-RNP complexes establishes and extends our understanding of the biochemical basis of how piwi/argonaute family members may function in the spatial and temporal translation of specific mRNAs during development (Carmell et al. 2002). Consequently, the findings reported here provide insight into the potential cellular mechanisms involved in specifying axis formation during early sea urchin development.

\section{RESULTS}

\section{Cloning of sea urchin 100-kDa protein by screening a cDNA library}

Electrophoretically purified $100-\mathrm{kDa}$ tubulin dimer binding protein was enzymatically digested and microsequences from five different peptides were obtained (Fig. 1A). Degenerate sense and antisense primers for RT-PCR were designed based on the peptide microsequences from three of the five peptides (Fig. 1A, underlined residues). A cDNA of 1730 bp was amplified and partially sequenced using degenerate primers for ELTSQIAK and MIIGIDSYH. Sixframe translation of the obtained sequence identified the presence of the GPEIV microsequence nested between ELTS

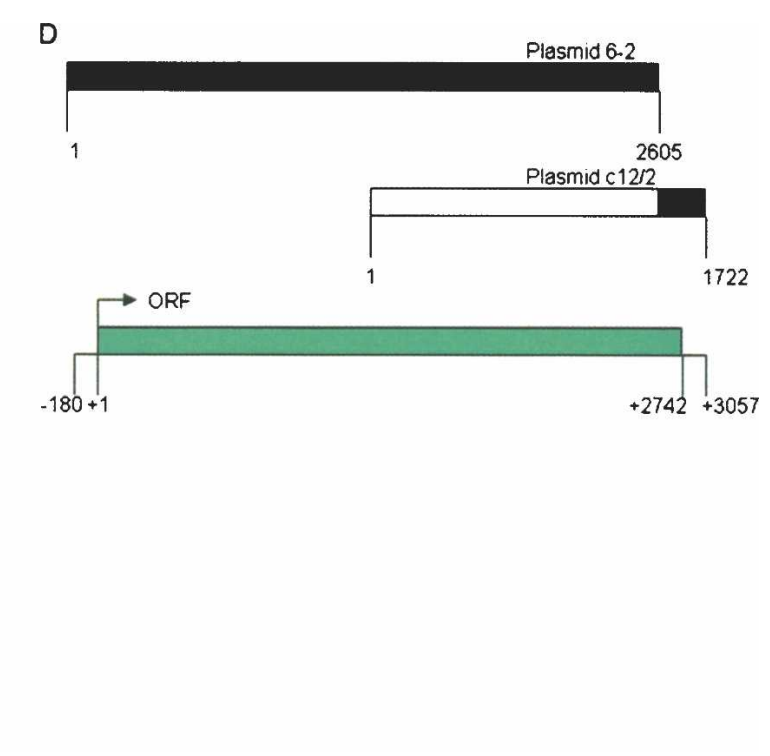

FIGURE 1. Molecular cloning of seawi. (A) The five peptide microsequences obtained following proteolytic degradation of the 100-kDa protein. The underlined residues highlight the sequences used for synthesis of degenerate primers. (B) Schematic representation of the result of RT-PCR of total egg RNA with PEIV and MIIG primers with the orientation of the primers shown with arrows. $(C)$ Alignment of the translated sequence of the 324-bp product with piwi and miwi generated using Vector NTI Suite 6.0 software (InforMax, Inc.) AlignX program. Residues identical in all three sequences are shown in red while residues identical in two of the sequences are shown in gray. $(D)$ Schematic representation of the products from cDNA library screening. The black areas in plasmid 6-2 and plasmid c12/2 show the areas used to determine the consensus sequence of the $100-\mathrm{kDa}$ protein. The bottom diagram shows key features of the consensus sequence. 
and MIIG. Specific primers to the PEIVEL portion of the GPEIV microsequence and the MIIGIDSYH portion of the VEIP microsequence were synthesized and used in RT-PCR to amplify a 324-bp product from total egg RNA (Fig. 1B). Searching the GenBank database using the translated sequence of the 324-bp fragment identified $46 \%$ and $36 \%$ identity between the amplified fragment and the corresponding regions of miwi and piwi, respectively (Fig. 1C).

A digoxygenin (DIG)-labeled probe complementary to the amplified 324-bp fragment was prepared and used to screen an $S$. purpuratus oocyte $\lambda Z A$ AP cDNA library. The initial screen identified plasmid 6-2 that contained a 2605bp insert (Fig. 1D; GenBank accession no. AY014900) that upon sequence analysis revealed the presence of a consensus Kozak sequence surrounding a start codon followed by an uninterrupted open reading frame with no downstream stop codon. A second DIG-labeled probe was synthesized using primer sequences derived from the $3^{\prime}$ end of plasmid 6-2 (specific sequences in Materials and Methods). Screening the cDNA library with the second probe resulted in the isolation of plasmid c12/2 (GenBank accession no. AY014901). Plasmid c12/2 contained a 1722-bp insert containing a long open reading frame with a stop codon near its $3^{\prime}$ end and had over $1000 \mathrm{bp}$ of overlapping sequence with plasmid 6-2 (Fig. 1D). Splicing together the plasmid sequences produced a single contiguous sequence of $3057 \mathrm{bp}$ containing a 2562-bp open reading frame (Fig. 1D) coding for a 854-amino-acid protein with a calculated molecular weight of 96,715 Da (Fig. 2A). As anticipated, all five of the peptide microsequences identified from the digests of the $100-\mathrm{kDa}$ protein were present within the deduced amino acid sequence of the cloned $100-\mathrm{kDa}$ protein (Fig. 2A, see asterisks).

\section{Sequence analysis of sea urchin 100-kDa protein}

A search of the GenBank database revealed that the cloned sequences were most closely related to sequences from members of the piwi/argonaute family of proteins. Overall, the amino acid sequence of the $100-\mathrm{kDa}$ protein was $35.7 \%$ identical and $52.5 \%$ similar to aubergine and $35.6 \%$ identical and $53.3 \%$ similar to piwi (Fig. 2A). Analysis of the $100-\mathrm{kDa}$ protein's deduced amino acid sequence using the Pfam database (St. Louis, MO) identified the presence of PAZ and piwi domains that are signature motifs (Cerutti et al. 2000) for the piwi/argonaute family of proteins (Fig. 2B). The PAZ domain extended from residues 236 to 402 and the piwi domain was located at the $\mathrm{C}$ terminus at residues 547-840 (Fig. 2B). PAZ domains of both piwi and argonaute family members have been shown to preferentially bind RNA, in particular siRNAs (Lingel et al. 2003, 2004; Ma et al. 2004). Kuramochi-Miyagawa et al. (2001) identified a 138 -amino-acid stretch located at the $5^{\prime}$ end of the mouse piwi domain (amino acids 541-678) that is necessary and sufficient for miwi's RNA binding property. Interest- ingly, the corresponding stretch (amino acids 532-669; Fig. $2 \mathrm{~B}$, see asterisks) for the $100-\mathrm{kDa}$ protein shares $55 \%$ identity and 69\% similarity with the mouse miwi RNA binding sequence; such a significant level of identity is probably indicative of functional equivalence as an RNA binding region in the $100-\mathrm{kDa}$ protein.

Phylogenetic analysis of 16 members of the piwi/argonaute family placed the $100-\mathrm{kDa}$ protein's amino acid sequence as being closely related to mouse miwi and human hiwi proteins (Fig. 2C), which cluster together within the piwi subgroup of the piwi/argonaute family. In keeping with the piwi nomenclature, the $100-\mathrm{kDa}$ sea urchin protein was named seawi, for sea urchin piwi (GenBank accession no. AY014899).

\section{Seawi is a major component of $S$. purpuratus MT-RNP complexes}

Sea urchin MT-RNP complexes, prepared by multiple rounds of temperature- and $\mathrm{pH}$-dependent cycling, contain a prominent $100-\mathrm{kDa}$ protein (Fig. 3A, lane 1) that appears to comigrate in SDS-PAGE with purified seawi samples (Fig. 3A, lane 2). Rabbit antisera were prepared using purified seawi and the $100-\mathrm{kDa}$ MT-RNP protein and used for immunoblot analysis to determine whether seawi is the 100$\mathrm{kDa}$ protein in sea urchin MT-RNP complexes. Both antiseawi (serum 4I4) and anti-100 kDa (serum A59) polyclonal sera bound to a single band of $100 \mathrm{kDa}$ in protein samples of S. purpuratus eggs (Fig. 3B, lanes 3,5). There was no detectable binding of preimmune sera for $4 \mathrm{I} 4$ or A59 to any specific protein band in total egg protein (Fig. 3B, lanes 4 and 6 , respectively) verifying the monospecificity of the two antisera.

To further assess the relatedness of the two $100-\mathrm{kDa}$ proteins, reciprocal immunoblots were performed using the monospecific antisera generated against the respective 100$\mathrm{kDa}$ polypeptides. Polyclonal antiserum 4I4 (raised against purified seawi) recognized both $100-\mathrm{kDa}$ proteins when used to probe a blot of the MT-RNP complex proteins and purified seawi transferred to nitrocellulose (Fig. 3C). Polyclonal antiserum A59 (prepared against the MT-RNP 100$\mathrm{kDa}$ protein) also recognized both $100-\mathrm{kDa}$ proteins (Fig. 3C). Additionally, both antisera crossreacted with a polypeptide of the expected molecular weight in lysates from bacteria overexpressing recombinant seawi from plasmid 6-2 but not in lysates from non-plasmid-carrying bacteria (data not shown). Combined, the above data establish that the two $100-\mathrm{kDa}$ proteins are immunologically related and that the $100-\mathrm{kDa}$ protein in MT-RNP complexes is seawi.

\section{Seawi interacts with intact ribosomes}

Preparations of sea urchin ribosomes, isolated by preparative sucrose step-gradients, contain a $100-\mathrm{kDa}$ polypeptide 
A

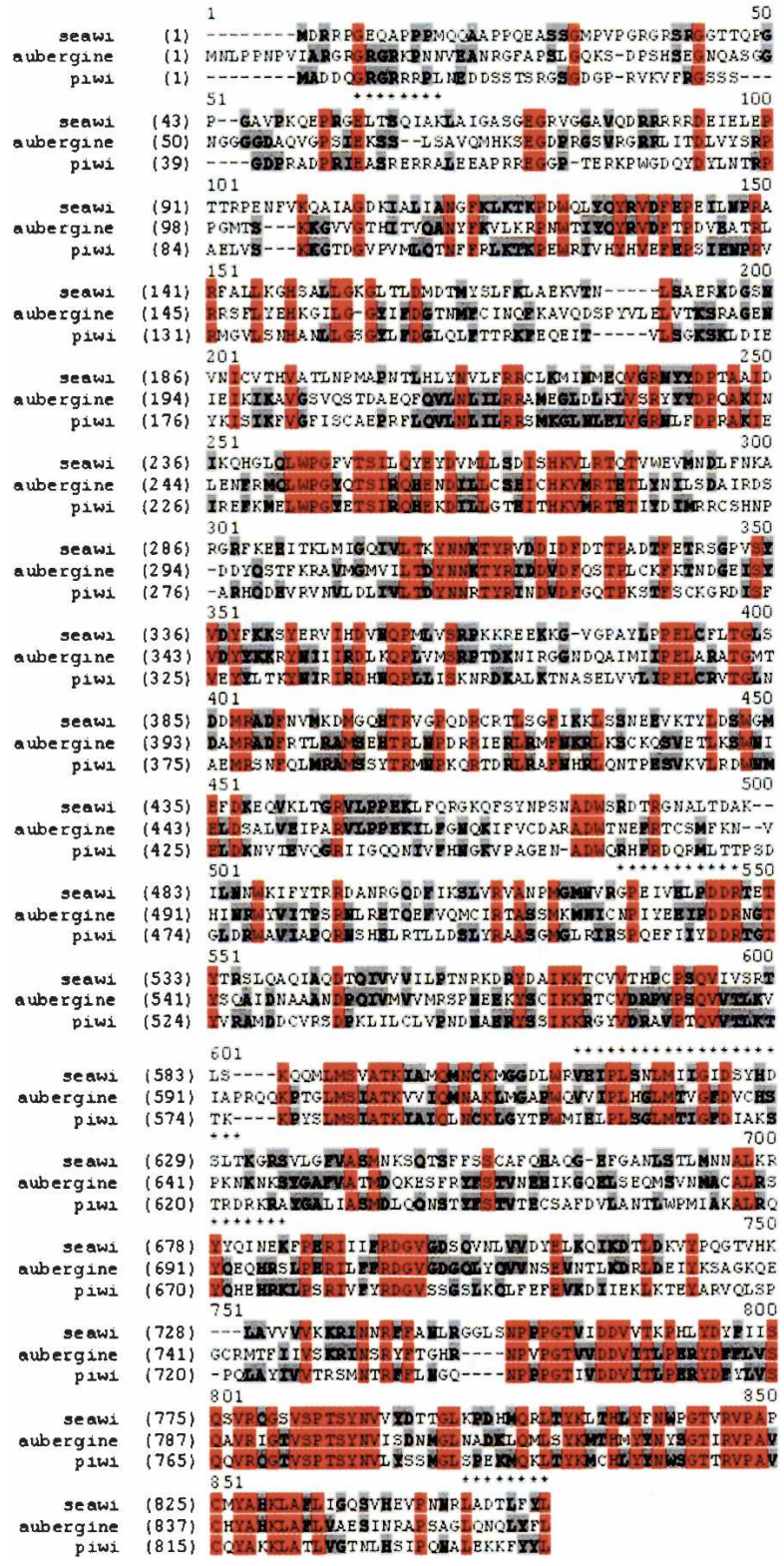

B

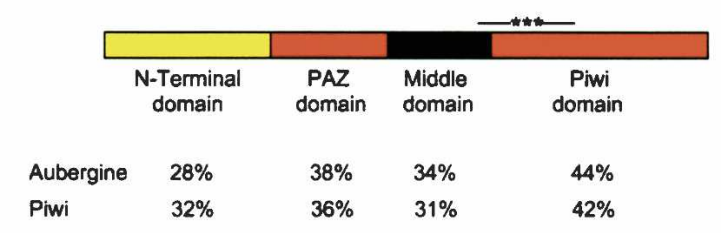

C

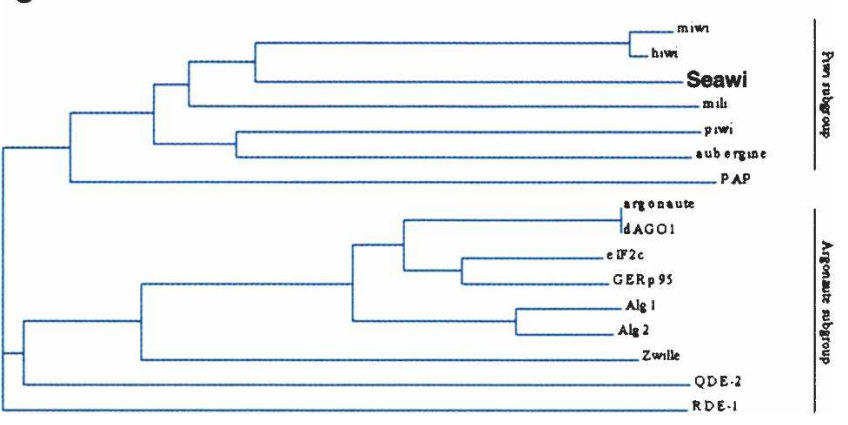

FIGURE 2. Classification of the $100-\mathrm{kDa}$ protein (seawi) as a member of the piwi family. (A) Alignment of the full-length sequence of the $100-\mathrm{kDa}$ protein with piwi and aubergine. Residues identical in all three sequences are shown in red while residues identical in two of the sequences are shown in gray. The asterisks above the seawi sequence identify the five peptide microsequences. (B) Domain organization of seawi. The level of identity of each of the domains with the corresponding regions from piwi and aubergine are shown. The asterisks above the piwi domain within seawi identify the putative mRNA binding domain based on sequence homology with miwi's mRNA binding sequence. ( $C$ ) Phylogenetic analysis generated using Vector NTI Suite Version 6.0 software AlignX program. Note, seawi clusters most closely to hiwi and miwi.

that comigrates with the seawi polypeptide in MT-RNP complexes (Fig. 4, cf. lanes 2 and 3). MT-RNP complexes and ribosome preparations were immunoblotted using antibodies raised against seawi, EMAP, alpha-tubulin, and a $40-\mathrm{kDa}$ protein of the ribosomal 40S subunit. Anti-seawi antibodies crossreacted strongly with the $100-\mathrm{kDa}$ protein present in both MT-RNP and ribosome preparations (Fig. 4 , lanes 4,5). Neither EMAP nor tubulin were detected in preparations of ribosomes (Fig. 4, lane 5), indicating that the association of seawi with biochemically purified ribosomes was not due to nonspecific association with contaminating MT-RNP complex proteins. As expected, antibodies against the $40-\mathrm{kDa}$ protein of the ribosomal $40 \mathrm{~S}$ subunit recognized a protein in both the MT-RNP preparation and the purified ribosome preparation.

To further establish the specific association of seawi with ribosomes, preparations of isolated ribosomes were sedimented through linear $15-40 \%$ sucrose gradients and the 
A

B

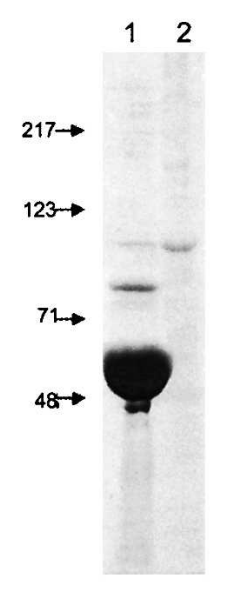

$\begin{array}{llllll}1 & 2 & 3 & 4 & 5 & 6\end{array}$

C

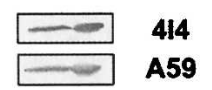

FIGURE 3. Seawi is the $100-\mathrm{kDa}$ protein of $S$. purpuratus MT-RNP complexes. (A) SDS-PAGE gel of MT-RNP complex proteins and purified seawi. (Lane 1) Isolated MT-RNP complex. (Lane 2) Purified seawi protein. (B) Characterization of seawi antisera. (Lane 1) Bio-Rad prestained high range SDS-PAGE standards (molecular weights are the same as those shown in A). (Lane 2) SDS-PAGE of total protein from $S$. purpuratus egg. (Lane 3) Immunoblot of total egg protein with anti-100-kDa protein polyclonal antiserum (4I4). (Lane 4) Immunoblot of total egg protein with preimmune serum for 4I4. (Lane 5) Immunoblot of total egg protein with anti-100-kDa MT-RNP complex protein polyclonal antiserum (A59). (Lane 6) Immunoblot of total egg protein with preimmune serum for A59. (C) Companion immunoblots to the SDS-PAGE of the MT-RNP complex (left lane) and purified seawi (right lane) shown in Panel A. Blots were probed using either anti-100-kDa protein polyclonal antiserum (4I4) or anti-100$\mathrm{kDa}$ MT-RNP complex protein polyclonal antiserum (A59); only the relevant portions of the blots are shown. Each antiserum binds to both of the $100-\mathrm{kDa}$ proteins, thus establishing their immuno-relatedness.

resultant gradient fractions were analyzed by SDS-PAGE and immunoblotting. Using salt conditions $(80 \mathrm{mM} \mathrm{KCl})$ that maintained the assembly of 80 S ribosomes, seawi sedimented in the same gradient fractions as $80 \mathrm{~S}$ ribosomes (Fig. 5A). When the entire gradient was examined by immunoblotting using anti-seawi antibodies, seawi was only detected in the fractions that contained the $40-\mathrm{kDa}$ ribosomal protein, suggesting a physical association between seawi and intact $80 \mathrm{~S}$ ribosomes (Fig. 5A). To further test this possibility, ribosome preparations were placed into buffer containing $500 \mathrm{mM} \mathrm{KCl}$ and then subjected to sedimentation analysis. Under these conditions, seawi sedimented toward the top of the gradient well removed from the gradient fractions that contain 40 or $60 \mathrm{~S}$ ribosomes (Fig. 5B). Immunoblotting with anti-seawi and anti-40-kDa ribosomal protein antibodies confirmed this conclusion (Fig. $5 \mathrm{~B})$. Thus, seawi is not only a major component of MT-
RNP complexes but is also co-isolated with preparations of purified sea urchin egg ribosomes.

\section{Seawi is a component of $P$. lividus MT-RNP complexes}

A common functional role among many piwi/argonaute family members is their participation in axis formation and/ or stem cell maintenance through a pathway reliant upon interaction with RNA (Carmell et al. 2002). Hamill et al. (1994) demonstrated that MT-RNP complexes appear to contain a specific subset of mRNAs that are not available for in vitro translation when associated with the MT-RNP complex. SDS-PAGE comparison of the protein profiles of MTRNP complexes prepared from $P$. lividus and $S$. purpuratus indicates that in addition to tubulin they share a remarkably similar protein composition with major bands at 107, 100, and $77 \mathrm{kDa}$ (Fig. 6, cf. lanes 1 and 2). Immunoblot analysis using anti-seawi antibodies was performed on $P$. lividus MT-RNP complexes (Romancino et al. 1998) to determine whether the $100-\mathrm{kDa}$ protein in the complexes was seawi. Anti-seawi antibodies crossreacted with a single band at 100 $\mathrm{kDa}$ indicating that seawi is a component of $P$. lividus MTRNP complexes (Fig. 6, lane 3). Interestingly, P. lividus MT-RNP complexes are known to carry bep4 mRNA, whose translation product, Bep4, has been shown to be differentially expressed and is believed to play an important role in P. lividus developmental axis formation (Romancino et al. 1998, 2001). Recently, we identified the association of bep4 mRNA with MT-RNP complexes isolated from S. purpuratus eggs (D.J. Desai, S.A. Seipel, A.J. Rodriquez, and E.M. Bonder, unpubl. observations).

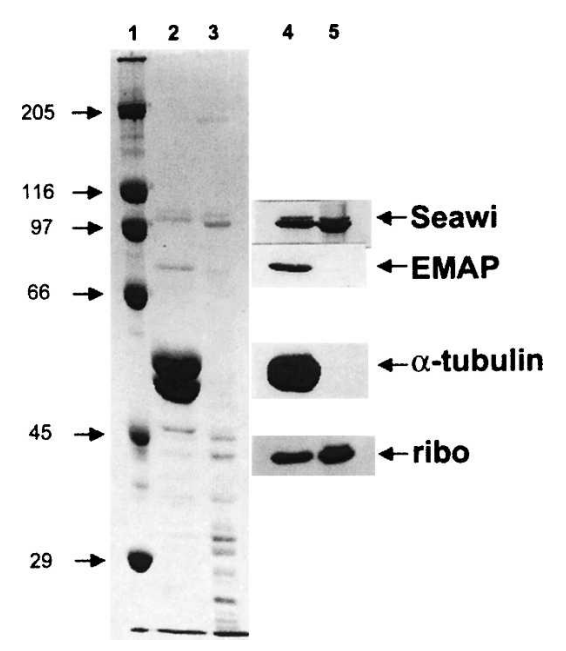

FIGURE 4. Seawi is a component of purified ribosome preparations. Coomassie blue stained gel of $S$. purpuratus MT-RNP complex and purified ribosome preparation are shown in lanes 2 and 3, respectively. Companion immunoblots (MT-RNP complex, lane 4; purified ribosome preparation, lane 5) were probed using antisera against the 100$\mathrm{kDa}$ protein/seawi (A59), EMAP, $\alpha$-tubulin, and a $40-\mathrm{kDa}$ component of ribosomes (ribo). Molecular weight standards are shown in lane 1 . 
A

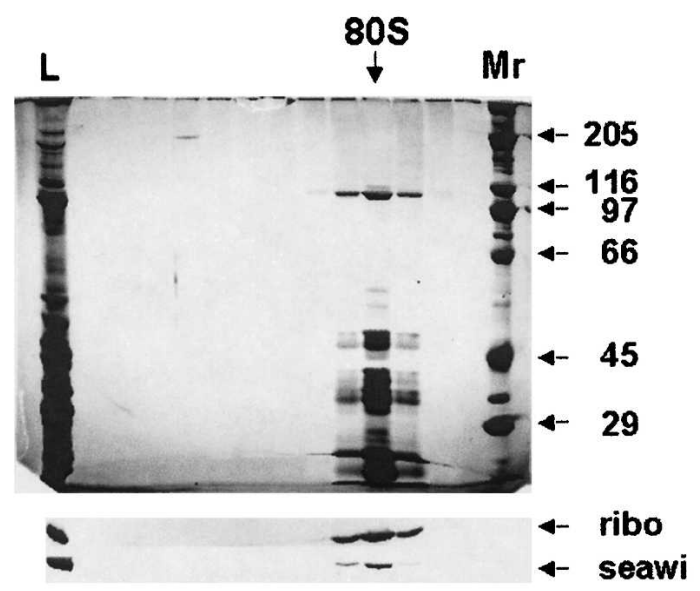

B

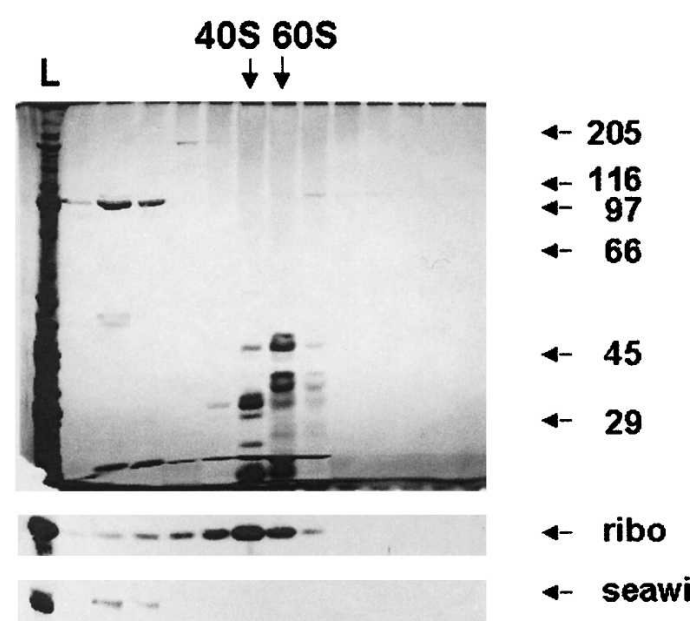

FIGURE 5. Sucrose density centrifugation analysis of $S$. purpuratus ribosome preparations. (A) Silver stained SDS-PAGE gel of the results of sucrose gradient centrifugation of purified egg ribosomes (lane $L$ ) with the corresponding regions of the companion immunoblots probed with A59 antiserum (seawi) and anti-40-kDa ribosomal protein (ribo). The position of the $80 \mathrm{~S}$ ribosome is indicated, demonstrating that seawi and the 80 S ribosome cosediment. The top of the gradient is at the left. (B) Silver stained SDS-PAGE gel of the results of sucrose gradient centrifugation of purified egg ribosomes following high salt treatment. The arrows indicate the positions of the dissociated $40 \mathrm{~S}$ and $60 \mathrm{~S}$ ribosomal subunits. Notice that seawi fails to cosediment with either of the ribosomal subunits under these conditions.

\section{Identification of seawi binding to bep4 message}

Previously, Montana et al. $(1997,1998)$ demonstrated that LP54, an RNA binding protein present in MT-RNP, was the only protein within MT-RNP complexes capable of binding the 3' UTR of bep3 RNA. Since seawi possesses both a PAZ and a piwi domain RNA binding motif (Kuramochi-Miyagawa et al. 2001; Lingel et al. 2003, 2004; Yan et al. 2003; Ma et al. 2004), we sought to determine whether seawi binds

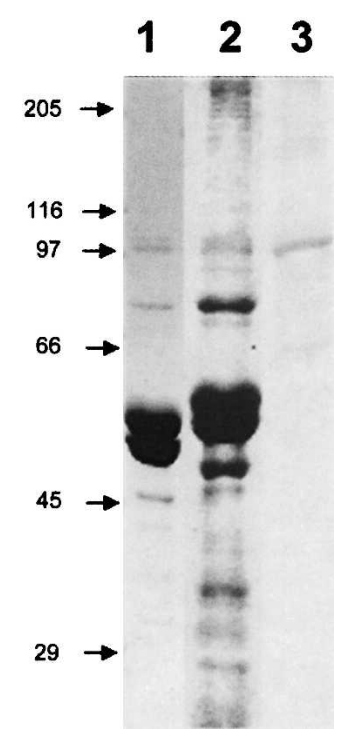

FIGURE 6. Comparison of $S$. purpuratus and P. lividus MT-RNP complexes. Coomassie blue stained SDS-PAGE gels of $S$. purpuratus (lane 1) and P. lividus (lane 2) MT-RNP complex preparation. (Lane 3) Result of an immunoblot of the P. lividus MT-RNP complex probed with anti-seawi antibodies (A59). directly to bep4 mRNA, which was previously shown to co-isolate with MT-RNP complexes (Romancino et al. 1998). P. lividus LP54, seawi, and fibronectin were transferred to nitrocellulose and the blotted protein was probed with DIG-labeled bep4 mRNA (Montana et al. 1997, 1998). Using this blotting method, both LP54 (Fig. 7, lane 1; positive control) and seawi (Fig. 7, lane 2) exhibited binding to bep4 message while the negative fibronectin control (Fig. 7, lane 3) demonstrated no binding to bep4 message.

\section{Seawi's mRNA and protein expression is developmentally regulated}

Relative RT-PCR and immunoblotting were used to examine the developmental expression pattern of seawi protein and mRNA during early $S$. purpuratus embryogenesis. PCR primer pairs for seawi and $18 \mathrm{~S}$ rRNA were PCR amplified through 21 cycles, which corresponded to the linear portion of the amplification cycle for the seawi product. The amplified product was normalized relative to the $18 \mathrm{~S}$ rRNA product and this ratio was compared to the equivalent value obtained for unfertilized eggs. To examine levels of protein across early embryogenesis, equal concentrations of total embryonic protein from staged embryos from a single SDSPAGE gel were transferred to nitrocellulose, probed with anti-seawi antibodies, and the results quantitated densitometrically relative to unfertilized eggs.

Both seawi mRNA and protein are maternally stored in the unfertilized egg. After fertilization, seawi mRNA levels gradually declined during the initial cleavage stages followed by a relatively rapid burst of expression that returned mRNA levels back to those of the unfertilized egg by the 


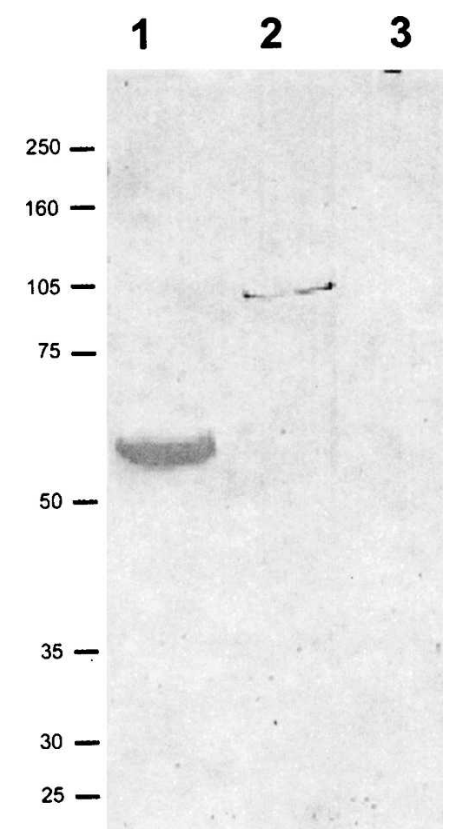

FIGURE 7. Seawi binds bep4 mRNAs. A Northwestern blot of purified LP54 (lane 1), purified seawi (lane 2), and purified fibronectin (lane 3) probed with full-length bep4 message. Notice that LP54 (previously shown to be an mRNA binding protein); (Montana et al. 1997) and seawi bind bep4 message while the control protein, fibronectin, does not.

mesenchyme blastula stage (Fig. 8). A second rise in message level was detected at the prism stage, by which time the embryo has formed its basic body plan that will carry it up to metamorphosis. The pattern for protein expression essentially corresponded to the mRNA profile with tempo-

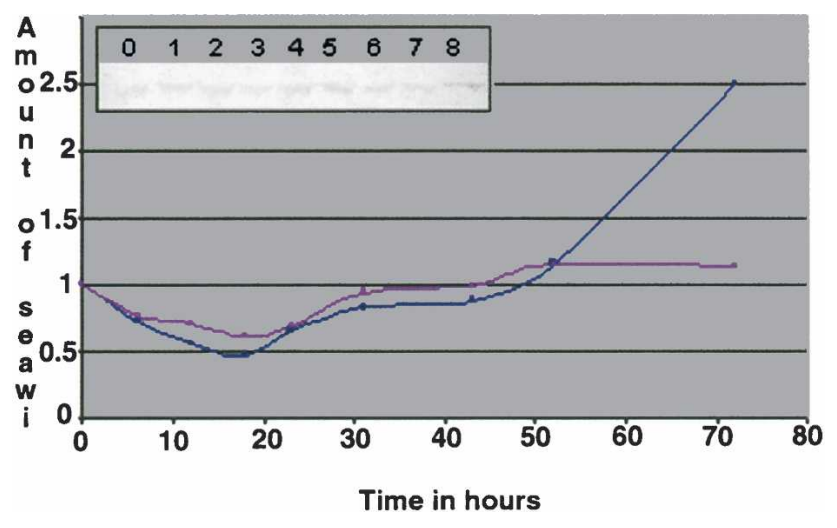

FIGURE 8. Developmental expression profile of seawi. Levels of seawi message (red) and protein (blue) present at different stages of development were normalized to the amount of message or protein found in the unfertilized eggs. (inset) Representative immunoblot of total $S$. purpuratus protein probed with A59 antiserum. The following stages were investigated: unfertilized eggs (lane 0$) ; 6 \mathrm{~h}, 4$ divisions (lane 1); $12 \mathrm{~h}, 8$ divisions (lane 2); $18 \mathrm{~h}$, late blastula (lane 3); $23 \mathrm{~h}$, primary mesenchyme ingression (lane 4); $31 \mathrm{~h}$, gastrula (lane 5); $42 \mathrm{~h}$, archenteron formation (lane 6); $52 \mathrm{~h}$, prism (lane 7 ); $72 \mathrm{~h}$, pluteus larva (lane 8). rally overlapping decreases and increases in the protein levels across development (Fig. 8).

\section{Immunolocalization of seawi}

Whole $S$. purpuratus eggs were stained for indirect immunofluorescence using anti-seawi antibodies and laser scanning confocal microscopy was used to examine the labeled eggs. Confocal microscopy images of labeled eggs detected the presence of a distinct 3-5- $\mu \mathrm{m}$-thick layer of enhanced fluorescence localized to the cortex of the unfertilized eggs (Fig. 9A). To further characterize this staining pattern, cortices of unfertilized eggs were prepared on glass coverslips and used for immunofluorescence labeling followed by confocal microscopy. Images of the cortical region of the unfertilized egg revealed a characteristic honeycomb pattern of labeling consistent with staining the cortical cytoplasm surrounding cortical granules docked at the plasma membrane (Fig. 9B). While the pattern appeared to be continuous at low magnification, at higher magnification the reticular pattern presented itself as closely spaced distinct puncta having dimensions of $\sim 250 \mathrm{~nm}$ (Fig. 9C). Interestingly, the cortex of sea urchin eggs is enriched with ribosomes and this cortical enrichment has been proposed to be a vehicle for differential segregation of mRNAs during division (Sardet et al. 2002). In first mitotic cycle embryos, seawi localization was not as restricted to the cortex of the cells as it was in unfertilized eggs (Fig. 9D). In addition to cytoplasmic staining, there was prominent seawi staining of the mitotic spindle. Inspection of spindle staining gives the impression that seawi is enriched at opposite poles of the mitotic spindle as compared to the equatorial region (Fig. 9D). To determine if seawi protein expression was spatially regulated during development, embryos were raised to the 16/ 32-cell stage and stained for seawi in order to examine the staining pattern along the animal-vegetal axis. Interestingly, there was a dramatic increase in the levels of seawi labeling within the four micromeres at the vegetal pole of the embryo (Fig. 9E).

\section{DISCUSSION}

\section{Seawi is a member of the piwi/argonaute protein family}

In this report, we establish that the previously isolated sea urchin egg $100-\mathrm{kDa}$ microtubule binding protein (seawi) is the sea urchin ortholog of Drosophila piwi. Seawi contains the signature motifs of the piwi/argonaute protein family, including a C-terminal piwi domain, a centrally located PAZ domain, and a N-terminal variable domain (Cerutti et al. 2000). The piwi domain is highly conserved across the entire family and recent findings suggest that a 138-aminoacid stretch within this domain is necessary and sufficient for miwi's RNA binding (Kuramochi-Miyagawa et al. 
A

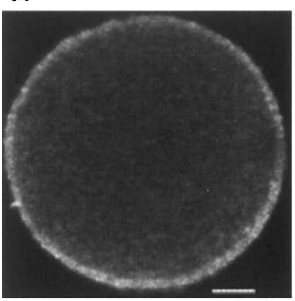

c

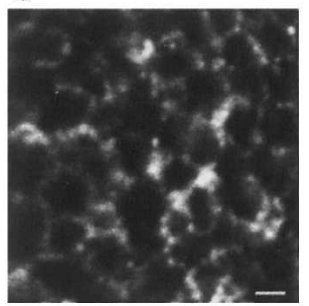

E

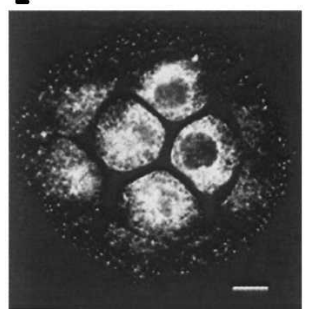

B

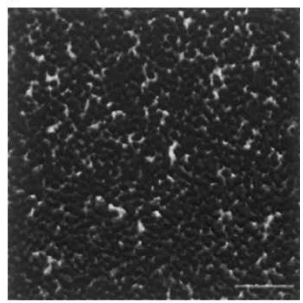

D

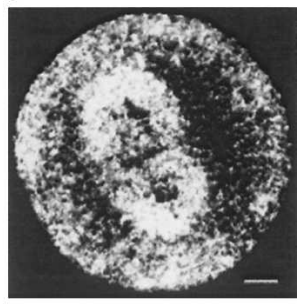

FIGURE 9. Immunolocalization of seawi. (A) Laser scanning confocal micrograph of an unfertilized S. purpuratus egg stained with A59 antiserum. (B) Laser scanning confocal micrograph of a cortical preparation of an unfertilized egg stained with $4 \mathrm{I} 4$ antiserum. $(C)$ Higher magnification of a laser scanning confocal micrograph of a cortical preparation of an unfertilized egg stained with 4I4 antiserum. (D) Laser scanning confocal micrograph of a first division $S$. purpuratus embryo stained with A59 antiserum. (E) Laser scanning confocal micrograph of an early cleavage stage $S$. purpuratus embryo stained with A59 antiserum. Notice the enrichment of seawi in the four micromeres present at the vegetal pole of the embryo. The bars in $A, B, D, E$ are $10 \mu \mathrm{m}$, while the bar in $C$ is $1 \mu \mathrm{m}$.

2001). Seawi and miwi are 55\% identical and $69 \%$ similar over those 138 amino acids, suggesting that this segment of seawi may mediate an interaction with mRNA. Recent crystal structures have identified that both the piwi and PAZ domains participate in RNA binding (Parker et al. 2004; Song et al. 2004). The PAZ domain was originally proposed to function as a protein-protein binding domain during translational silencing (Hammond et al. 2001; Moss 2001) and more recently it has been shown to bind to RNAs, including siRNA with a 1:1 stoichiometry (Lingel et al. 2003, 2004; Yan et al. 2003). This binding interaction is fascinating and informative given the emerging importance of piwi/argonaute family members and si- and micro-RNAs in RNA silencing processes (Carmell et al. 2002; Rand et al. 2004). The highly variable $\mathrm{N}$-terminal domain may reflect functional specialization of individual piwi/argonaute family members, thereby providing the observed breadth of functionality such as stem cell establishment and maintenance (piwi, Cox et al. 1998; miwi, Kuramochi-Miyagawa et

al. 2001; hiwi, Sharma et al. 2001), RNAi (argonaute-2, Hammond et al. 2001; RDE-1, Tabara et al. 1999), posttranscriptional silencing (argonaute-1, Fagard et al. 2000; aubergine, Wilson et al. 1996; Harris and Macdonald 2001), and localization of transcripts (aubergine, Wilson et al. 1996). Lastly, phylogenetic analysis of the piwi/argonaute family shows that seawi clusters within the piwi subgroup whose members are functionally associated with the maintenance of stem cell populations and/or axis formation.

\section{Seawi and its potential role in sea urchin embryogenesis}

Could seawi have a role in sea urchin axis formation and establishment of set-aside cells similar to the role of piwi/ argonaute family members during Drosophila development? Drosophila piwi family member aubergine is required for the proper translation and localization of gurken, oskar, and nanos mRNAs whose translation products are subsequently needed for determining dorsal-ventral and anterior-posterior patterning (Wilson et al. 1996). Also, aubergine localizes to polar granules, the cytoplasmic site that will give rise to pole cells, a group of stem cells required for germline development in Drosophila (Harris and Macdonald 2001). Interestingly, aubergine is also linked to RNAi activity in oocytes (Kennerdell et al. 2002). Similar localization patterns for aubergine and vasa, an eIF-4A homolog, coupled with the observation that vasa recruits the Drosophila homolog of eIF-2 to certain mRNAs, suggests that subsets of mRNAs are preassembled into translational initiation complexes (Carrera et al. 2000; Harris and Macdonald 2001). Activation of such preassembled complexes might require site-specific recruitment of other "translation activation factors" making it possible to spatially and temporally regulate protein expression of developmentally important transcripts such as oskar and nanos (Lipshitz and Smibert 2000).

During the initial stages of sea urchin embryogenesis three distinct cell fate domains are established along the animal-vegetal axis. At the vegetal pole, nuclear $\beta$-catenin interacts with Tcf/Lef transcriptional regulators to initiate the transcription of numerous genes including Wnt8, Krl, Krox, and Pmarl (Vonica et al. 2000; Davidson et al. 2002). These factors initiate a cascade of transcription that establishes the "vegetal signaling mechanism," which patterns vegetal blastomeres and specifies mesenchyme and endoderm (Angerer and Angerer 2000; Davidson et al. 2002). The molecular mechanism regulating the spatial and temporal entry of $\beta$-catenin into the nucleus is cell autonomous and requires factors of maternal origin (Davidson et al. 2002).

In P. lividus embryos, Bep4 protein colocalizes with cadherin and $\beta$-catenin at cell-cell junctions of cells at the animal pole while in micromeres there is no junctional Bep4 or $\beta$-catenin; instead there is an enhanced level of nuclear $\beta$-catenin (Romancino et al. 2001). Using anti-Bep4 antibodies, it was possible to disrupt normal axis specifica- 
tion by allowing the domain of nuclear $\beta$-catenin to expand toward the animal pole, suggesting that inhibition of Bep4 function effected the subcellular localization and physiological activity of $\beta$-catenin (Romancino et al. 2001). Bep4 may maintain $\beta$-catenin in the cytoplasm by participating in junctional assembly, thus preventing $\beta$-catenin entry into the nucleus and subsequent initiation of vegetal transcriptional signaling (Aplin and Juliano 2001).

By analogy with the role of aubergine in the translational regulation of oskar and the role of Drosophila argonaute-1 in the regulation of the $\beta$-catenin pathway, seawi-containing RNP complexes could regulate the spatial/temporal expression of RNP associated mRNA including the bep4 transcript. After fertilization, the levels of seawi message and protein initially decrease followed by an increase in seawi expression that correlates temporally with the loss of $\beta$-catenin from adherens junctions in cells destined to ingress into the blastocoel during gastrulation (Miller and McClay 1997). The second embryonic rise in seawi expression correlates in time with the establishment of the coelomic pouches, a group of set-aside ("stem") cells that eventually comprise a significant portion of the adult rudiment (Peterson et al. 1997). Confocal microscopy of embryos stained by indirect immunofluorescence document an enhanced staining for seawi within the micromeres as compared to the other blastomeres. A recent preliminary report identified that sea urchin vasa (Voronina et al. 2004), whose Drosophila homolog is involved in regulating developmental transcripts oskar and nanos, shares an enhanced micromere localization pattern similar to what we identify for seawi. Further, the observed increase in seawi protein within micromeres temporally coincides with a decrease in micromere expression of Bep4 protein (Romancino et al. 2001 ), loss of $\beta$-catenin from micromere junctions (Miller and McClay 1997), and an increase in $\beta$-catenin within nuclei of micromeres (Logan et al. 1999; Romancino et al. 2001). Importantly, the timing of these events correlates with the beginning of nuclear $\beta$-catenin signaling during fate specification of the micromeres and the entire vegetal region of the embryo (Davidson et al. 2002). Consequently, the observed timing of expression and localization of seawi within the developing embryo coupled with its biochemical properties provide strong evidence that seawi might participate in modulating embryonic axis specification and formation.

The observation that seawi and ribosomes (Suprenant et al. 1989) are associated with the microtubules of the mitotic spindle provides an avenue for spatial segregation and anchorage of RNP complexes within the developing embryo. Once spatially segregated, translational activation of localized and arrested complexes may require subsequent assembly and activation of the translational machinery as elegantly shown in Drosophila (Carrera et al. 2000; Lipshitz and Smibert 2000; Harris and Macdonald 2001). Segregation and assembly of seawi- (and possibly vasa) associated translationally silencing RNP complexes to micromeres provides a mechanism for temporal and spatial regulation of Bep4 protein expression, which in turn would effect $\beta$-catenin localization.

Recently, RNP complexes containing piwi/argonaute family members and miRNAs have been shown to associate with polyribosomes (Nelson et al. 2004). This is interesting in light of miRNAs having a central role in the regulation of protein levels in many organisms through the degradation of message via RNAi or through the translation silencing of specific mRNAs via a complex between the miRNAs and the $3^{\prime}$ UTRs of the silenced message (Carmell et al. 2002). The regulation of expression of specific messages via miRNA is most clearly demonstrated by the role of this pathway in lineage specification during vertebrate hematopoiesis (Chen et al. 2004). Whether similar pathways are in play during sea urchin embryogenesis remains a matter for speculation and is presently under investigation.

\section{MATERIALS AND METHODS}

\section{cDNA library screening}

The 100-kDa dynamin-like protein was purified from unfertilized S. purpuratus eggs utilizing tubulin dimer affinity chromatography (Faire and Bonder 1993). Purified protein was electrophoretically transferred to nitrocellulose and processed for microsequence analysis at the Univerisity of Massachusetts Medical School Proteomic Mass Spectrometry Lab (formerly the W.M. Keck Protein Facility at the Worcester Foundation for Experimental Biology, Shrewsbury, MA). Degenerate primers were prepared based on the peptide microsequences and used for initial reverse transcriptionpolymerase chain reaction (RT-PCR) amplification and nucleotide sequencing of PCR products. Partial nucleotide sequence information was used to prepare sequence-specific primers for the GPEIV (5'-gaccagaaatagtggaacttcc-3') and MIIGcom (5'-gtggtag gagtcgatgccgatgatcat- $3^{\prime}$ ) sequences. RT-PCR was performed using total RNA isolated from unfertilized eggs and the GPEIV and MIIGcom primers. The resulting cDNA was gel purified using a QIAquick gel extraction kit (Qiagen Inc.) and sequenced using a Perkin Elmer DNA sequencing kit, the GPEIV and MIIGcom primers, and an Applied Biosystems ABI Prism 373 automated sequencer. GPEIV and MIIGcom primers were used to prepare a DIG-labeled probe for screening a $\lambda$ ZAP cDNA library as previously described (Sirotkin et al. 2000). A second DIG-labeled probe was synthesized using PCR primers C-term ( $5^{\prime}$ - cggacactctgactgat gatgaag- $\left.3^{\prime}\right)$ and C-termcom (5'-caacgagaagtttcctgagcgtatc- $\left.3^{\prime}\right)$ from the C-terminal portion of plasmid 6-2. Isolated plasmids were sequenced by several rounds of "primer walking."

\section{Relative RT-PCR analysis of staged embryos}

Sea urchin eggs and staged embryos were cultured as previously described (Sirotkin et al. 2000) and total RNA was isolated using the Biotecx Ultraspec RNA Isolation System. RNA from each stage was subjected to relative RT-PCR analysis as described by Ambion using the primers n5 seawi ( $5^{\prime}$-ccgggatccgaacaagcacccccaccgatg- $\left.3^{\prime}\right)$ and $\mathrm{n} 3$ seawi $\left(5^{\prime}\right.$-caccaccctcgagttaagacagcagcatcacgtcgtac- $\left.3^{\prime}\right)$. Two percent agarose gels of 21 cycle PCR products were stained with 
SYBR Gold Nucleic Acid Gel Stain (Molecular Probes) for $40 \mathrm{~min}$ and the resultant 18S/Seawi bands were quantitated using Metamorph software (Universal Imaging Corp.).

\section{MT-RNP complex and ribosome preparations}

MT-RNP complexes were purified from unfertilized S. purpuratus or $P$. lividus eggs by three cycles of $\mathrm{pH}$ - and temperature-dependent MT assembly and disassembly as previously described (Suprenant and Marsh 1987). Monoribosomes were purified from unfertilized eggs exactly as described by Hille and Danilchik (1986) with the exception that $200 \mu \mathrm{M}$ phenylmethlylsulfonyl fluoride (PMSF) was used instead of soybean trypsin inhibitor.

\section{Sucrose density centrifugation}

Linear $15 \%-40 \%(\mathrm{w} / \mathrm{v})$ sucrose gradients were prepared in buffer containing 80 or $500 \mathrm{mM} \mathrm{KCl}, 100 \mathrm{mM}$ potassium acetate, $5 \mathrm{mM}$ magnesium acetate, $9.9 \mathrm{mM} \mathrm{K}_{2} \mathrm{HPO}_{4}, 10.1 \mathrm{mM} \mathrm{KH}_{2} \mathrm{PO}_{4}$ (pH 6.8), and $200 \mu \mathrm{M}$ PMSF. After brief centrifugation (10 min, 39,000g, $\left.4^{\circ} \mathrm{C}\right) 1 \mathrm{~mL}$ of purified monoribosomes (1-2 mg) was overlayed onto a $12-\mathrm{mL}$ gradient and centrifuged in a SW41Ti swinging bucket rotor (Beckman Instruments) at 32,500 rpm $(150,000 \mathrm{~g})$ for $8 \mathrm{~h}$ at $4^{\circ} \mathrm{C}$. One-milliliter fractions were collected and analyzed by SDS-PAGE and immunoblotting.

\section{Polyclonal antibody production and characterization}

Preparation and characterization of polyclonal anti-100-kDa serum (4I4) was previously described (Faire and Bonder 1993). Briefly, egg 100-kDa protein purified from unfertilized Lytechinus pictus eggs (Faire and Bonder 1993) was run on 7.5\%-15\% SDSPAGE and lightly stained with Coomassie brilliant blue. The 100$\mathrm{kDa}$ protein was excised, frozen in liquid $\mathrm{N}_{2}$, finely ground with a mortar and pestle, emulsified with an equal volume of Freund's complete adjuvant, and used to immunize a New Zealand white rabbit.

Polyclonal antiserum (A59) against the 100-kDa MT-RNP complex protein was generated against third-cycle microtubule preparations. The MT-RNP complex proteins were separated by SDSPAGE and briefly stained with Coomassie brilliant blue. The 100$\mathrm{kDa}$ protein was excised, electroeluted, dialyzed into PBS, emulsified with Freund's complete adjuvant, and used to immunize a New Zealand white rabbit.

\section{Protein-RNA (Northwestern) blotting}

Purified LP54 (100 ng; as a positive control), purified seawi (100 $\mathrm{ng})$, and fibronectin (200 ng; as a negative control) were electrophoresed in an $8 \%$ SDS-polyacrylamide gel and blotted onto nitrocellulose. The blot was incubated in blocking buffer $(5 \times$ Denhardt's, $20 \mu \mathrm{g} / \mathrm{mL}$ tRNA, $1 \mathrm{nM}$ dUTP) for $1 \mathrm{~h}$ at $25^{\circ} \mathrm{C}$. RNA binding was carried out in blocking buffer with $3 \mathrm{ng} / \mathrm{mL}$ of DIGlabeled bep4 RNA for $2 \mathrm{~h}$ at $25^{\circ} \mathrm{C}$. The filter was subsequently washed for $15 \mathrm{~min}$ each in binding buffer (BB) $(10 \mathrm{mM}$ Tris at $\mathrm{pH}$ 7.5, $50 \mathrm{mM} \mathrm{NaCl}, 1 \mathrm{mM}$ EDTA), $4 \times \mathrm{BB}$, and $8 \times \mathrm{BB}$. The RNA was bound to membrane using a UV lamp $(254 \mathrm{~nm})$ and processed as described by Montana et al. (1997).

\section{Immunocytochemistry and immunoblotting studies}

Indirect immunofluorescence localization was conducted on eggs, embryos (Bonder et al. 1989), and isolated cortical lawns (Faire and Bonder 1993). Fixed cells, embryos, and cortical lawns were incubated in a 1:50 dilution of primary antibody (4I4 or A59) followed by a 1:500 dilution of Texas Red conjugated goat antirabbit secondary antibodies (Molecular Probes) and images were collected using a BioRad MRC 1024 laser scanning confocal microscope equipped with Nikon optics. Immunoblots with antiseawi antibodies (antisera 4I4 and A59) were performed at a 1: 5000 dilution of primary antibody followed by incubation in a 1:20,000 dilution of alkaline phosphatase conjugated goat antirabbit secondary antibodies. Developmental expression profiles of seawi protein were obtained by transferring equivalent concentrations of total egg/embryo protein to nitrocellulose and probing with antiserum A59. The intensities of the bands were quantitated using Metamorph software. Recombinant seawi protein was produced by overexpression in SOLR cells containing pBluescript plasmids containing the 6.2 seawi insert. Cultures were grown at $37^{\circ} \mathrm{C}$ to an $\mathrm{OD}_{600}$ of $\sim 0.6$ and brought to $10 \mathrm{mM}$ IPTG for $3 \mathrm{~h}$ before centrifugation at $7000 \mathrm{rpm}$ in an SS34 rotor to harvest the bacteria. Gel samples were prepared by resuspending the pellet in 20 volumes of $1 \times$ SDS-PAGE sample buffer. Control plasmids not containing the insert were overexpressed as described above.

\section{ACKNOWLEDGMENTS}

We gratefully acknowledge the many members of our labs that contributed moral support, extra sets of hands, lively discussion, and senses of humor during the long process of characterizing seawi. This work was supported by grants from the National Science Foundation RTG Program, National Institutes of HealthMBRS Program, Italian National Council of Research, and a Johnson and Johnson Discovery Award.

Received October 11, 2004; accepted February 15, 2005.

\section{REFERENCES}

Angerer, L.M. and Angerer, R.C. 2000. Animal-vegetal axis patterning mechanisms in the early sea urchin embryo. Dev. Biol. 218: 1-12.

Aplin, A.E. and Juliano, R.L. 2001. Regulation of nucleocytoplasmic trafficking by cell adhesion receptors and the cytoskeleton. J. Cell Biol. 155: 187-191.

Barbarese, E., Koppel, D.E., Deutscher, M.P., Smith, C.L., Ainger, K., Morgan, F., and Carson, J.H. 1995. Protein translation components are colocalized in granules in oligodendrocytes. J. Cell Sci. 108: 2781-2790.

Bonder, E.M., Fishkind, D.J., Cotran, N.M., and Begg, D.A. 1989. The cortical actin-membrane cytoskeleton of unfertilized sea urchin eggs: Analysis of the spatial organization and relationship of filamentous actin, nonfilamentous actin, and egg spectrin. Dev. Biol. 134: $327-341$.

Brandhorst, B.P. and Klein, W.H. 2002. Molecular patterning along the sea urchin animal-vegetal axis. Int. Rev. Cytol. 213: 183-232.

Carmell, M.A., Xuan, Z., Zhang, M.Q., and Hannon, G.J. 2002. The Argonaute family: Tentacles that reach into RNAi, developmental control, and tumorigenesis. Genes \& Dev. 16: 2733-2742.

Carrera, P., Johnstone, O., Nakamura, A., Casanova, J., Jackle, H., and Lasko, P., 2000. VASA mediates translation through interaction with a Drosophila yIF2 homolog. Mol. Cell 5: 181-187.

Cerutti, L., Mian, N., and Bateman, A. 2000. Domains in gene silencing and cell differentiation proteins: The novel PAZ domain and redefinition of the Piwi domain. Trends Biochem. Sci. 25: 481-482.

Chen, C.Z., Li, L., Lodish, H.F., and Bartel, D.P. 2004. MicroRNAs modulate hematopoietic lineage differentiation. Science 303: 83-86. 
Cox, D.N., Chao, A., Baker, J., Chang, L., Qiao, D., and Lin, H. 1998. A novel class of evolutionarily conserved genes defined by piwi are essential for stem cell self-renewal. Genes \& Dev. 12: 3715-3727.

Davidson, E.H. 1986. Gene Activity in Early Development, 4th ed. Academic Press, Inc., Orlando.

Davidson, E.H., Rast, J.P., Oliveri, P., Ransick, A., Calestani, C., Yuh, C.H., Minokawa, T., Amore, G., Hinman, V., Arenas-Mena, C., et al. 2002. A genomic regulatory network for development. Science 295: 1669-1678.

Fagard, M., Boutet, S., Morel, J.B., Bellini, C., and Vaucheret, H. 2000. AGO1, QDE-2, and RDE-1 are related proteins required for posttranscriptional gene silencing in plants, quelling in fungi, and RNA interference in animals. Proc. Natl. Acad. Sci. 97: 11650-11654.

Faire, K. and Bonder, E.M. 1993. Sea urchin egg 100-kDa dynaminrelated protein: Identification of and localization to intracellular vesicles. Dev. Biol. 159: 581-594.

Gibbins, J.R., Tilney, L.G., and Porter, K.R. 1969. Microtubules in the formation and development of the primary mesenchyme in Arbacia punctulata. I. The distribution of microtubules. J. Cell Biol. 41: 201-226.

Hamill, D.R., and Suprenant, K.A. 1997. Characterization of the sea urchin major vault protein: A possible role for vault ribonucleoprotein particles in nucleocytoplasmic transport. Dev. Biol. 190: $117-128$.

Hamill, D., Davis, J., Drawbridge, J., and Suprenant, K.A. 1994. Polyribosome targeting to microtubules: Enrichment of specific mRNAs in a reconstituted microtubule preparation from sea urchin embryos. J. Cell Biol. 127: 973-984.

Hammond, S.M., Boettcher, S., Caudy, A.A., Kobayashi, R., and Hannon, G.J. 2001. Argonaute2, a link between genetic and biochemical analyses of RNAi. Science 293: 1146-1150.

Harris, A.N. and Macdonald, P.M. 2001. Aubergine encodes a Drosophila polar granule component required for pole cell formation and related to eIF2C. Development 128: 2823-2832.

Hille, M.B. and Danilchik, M.V. 1986. The protein synthetic machinery: Ribosomes and cell-free systems. Methods Cell Biol. 27: 175-188.

Hirokawa, N., Takemura, R., and Hisanaga, S. 1985. Cytoskeletal architecture of isolated mitotic spindle with special reference to microtubule-associated proteins and cytoplasmic dynein. J. Cell Biol. 101: $1858-1870$.

Kennerdell, J.R., Yamaguchi, S., and Carthew, R.W. 2002. RNAi is activated during Drosophila oocyte maturation in a manner dependent on aubergine and spindle-E. Genes \& Dev. 16: 1884-1889.

Knowles, R.B., Sabry, J.H., Martone, M.E., Deerinck, T.J., Ellisman, M.H., Bassell, G.J., and Kosik, K.S. 1996. Translocation of RNA granules in living neurons. J. Neurosci. 16: 7812-7820.

Kuramochi-Miyagawa, S., Kimura, T., Yomogida, K., Kuroiwa, A., Tadokoro, Y., Fujita, Y., Sato, M., Matsuda, Y., and Nakano, T. 2001. Two mouse piwi-related genes: miwi and mili. Mech. Dev. 108: 121-133.

Lingel, A., Simon, B., Izaurralde, E., and Sattler, M. 2003. Structure and nucleic-acid binding of the Drosophila Argonaute 2 PAZ domain. Nature 426: 465-469.

2004. Nucleic acid 3'-end recognition by the Argonaute2 PAZ domain. Nat. Struct. Mol. Biol. 426: 576-577.

Lipshitz, H.D. and Smibert, C.A. 2000. Mechanisms of RNA localization and translational regulation. Curr. Opin. Genet. Dev. 10: 476-488.

Logan, C.Y., Miller, J.R., Ferkowicz, M.J., and McClay, D.R. 1999. Nuclear beta-catenin is required to specify vegetal cell fates in the sea urchin embryo. Development 126: 345-357.

Ma, J.B., Ye, K., and Patel, D.J. 2004. Structural basis for overhangspecific small interfering RNA recognition by the PAZ domain. Nature 429: 318-322.

Miller, J.R. and McClay, D.R. 1997. Changes in the pattern of adherens junction-associated beta-catenin accompany morphogenesis in the sea urchin embryo. Dev. Biol. 192: 310-322.

Montana, G., Bonura, A., Romancino, D.P., Sbisa, E., and DiCarlo, M. 1997. A $54 \mathrm{kDa}$ protein specifically associates the $3^{\prime}$ untranslated region of three maternal mRNAs with the cytoskeleton of the animal part of the Paracentrotus lividus egg. Eur. J. Biochem. 247: 183-198.
Montana, G., Sbisa, E., Romancino, D.P., Bonura, A., and DiCarlo, M. 1998. Folding and binding activity of the 3'UTRs of Paracentrotus lividus bep messengers. FEBS Lett. 425: 157-160.

Moss, E.G. 2001. RNA interference: It's a small world. Curr. Biol. 11: R772-R775.

Nelson, P.T., Hatzigeorgiou, A.G., and Mourelatos, Z. 2004. miRNP: mRNA association in polysomes in human neuronal cell line. $R N A$ 10: 387-394.

Parker, J.S., Roe, S.M., and Barford, D. 2004. Crystal structure of a PIWI protein suggests mechanisms for siRNA recognition and slicer activity. EMBO J. 23: 4727-4737.

Peterson, K.J., Cameron, R.A., and Davidson, E.H. 1997. Set-aside cells in maximal indirect development: Evolutionary and developmental significance. Bioessays 19: 623-631.

Pokrywka, N.J. and Stephenson, E.C. 1995. Microtubules are a general component of mRNA localization systems in Drosophila oocytes. Dev. Biol. 167: 363-370.

Rand, T.A., Ginalski, K., Grishin, N.V., and Wang, X. 2004. Biochemical identification of Argonaute 2 as the sole protein required for RNA-induced silencing complex activity. Proc. Natl. Acad. Sci. 101: 14385-14389.

Romancino, D.P. and Di Carlo, M. 1999. Asymmetrical localization and segregation of Paracentrotus lividus Bep4 maternal protein. Mech. Dev. 87: 3-9.

Romancino, D.P., Montana, G., and Di Carlo, M. 1998. Involvement of the cytoskeleton in localization of Paracentrotus lividus maternal BEP mRNAs and proteins. Exp. Cell Res. 238: 101-109.

Romancino, D.P., Montana, G., Dalmazio, S., and Di Carlo, M. 2001. Bep4 protein is involved in patterning along the animal-vegetal axis in the Paracentrotus lividus embryo. Dev. Biol. 234: 107-119.

Runnstrom, J. 1929. Uber selbstfifferenzierung and induction bei dem seeigelkeim. With. Roux Arch. 117: 123-145.

Sardet, C., Prodon, F., Dumollard, R., Chang, P., and Chenevert, J. 2002. Structure and function of the egg cortex from oogenesis through fertilization. Dev. Biol. 241: 1-23.

Sharma, A.K., Nelson, M.C., Brandt, J.E., Wessman, M., Mahmud, N., Weller, K.P., and Hoffman, R. 2001. Human CD34(+) stem cells express the hiwi gene, a human homologue of the Drosophila gene piwi. Blood 97: 426-434.

Sirotkin, V., Seipel, S., Krendel, M., and Bonder, E.M. 2000. Characterization of sea urchin unconventional myosins and analysis of their patterns of expression during early embryogenesis. Mol. Reprod. Dev. 57: 111-126.

Song, J.J., Smith, S.K., Hannon, G.J., and Joshua-Tor, L. 2004. Crystal structure of Argonaute and its implications for RISC slicer activity. Science. 305: 1434-1437.

Suprenant, K.A. and Marsh, J.C. 1987. Temperature and $\mathrm{pH}$ govern the self-assembly of microtubules from unfertilized sea-urchin egg extracts. J. Cell Sci. 87: 71-84.

Suprenant, K.A., Tempero, L.B., and Hammer, L.E. 1989. Association of ribosomes with in vitro assembled microtubules. Cell Motil. Cytoskeleton 14: 401-415.

Tabara, H., Sarkissian, M., Kelly, W.G., Fleenor, J., Grishok, A., Timmons, L., Fire, A., and Mello, C.C. 1999. The rde-1 gene, RNA interference, and transposon silencing in C. elegans. Cell 99: 123-132.

Vonica, A., Weng, W., Gumbiner, B.M., and Venuti, J.M. 2000. TCF is the nuclear effector of the beta-catenin signal that patterns the sea urchin animal-vegetal axis. Dev. Biol. 217: 230-243.

Voronina, E., Lopez, M.E., Song, J., Gustafson, E., Oliveri, P., Ransick, A., McClay, D.R., and Wessel, G.M. 2004. Germ cell formation in the sea urchin. Mol. Biol. Cell (Suppl.) 15: 135a.

Wilson, E.B. 1925. The cell in development and heredity, 3d ed. Macmillan, New York.

Wilson, J.E., Connell, J.E., and Macdonald, P.M. 1996. aubergine enhances oskar translation in the Drosophila ovary. Development 122: $1631-1639$.

Yan, K.S., Yan, S., Farooq, A., Han, A., Zeng, L., and Zhou, M.M. 2003. Structure and conserved RNA binding of the PAZ domain. Nature 426: 468-474. 

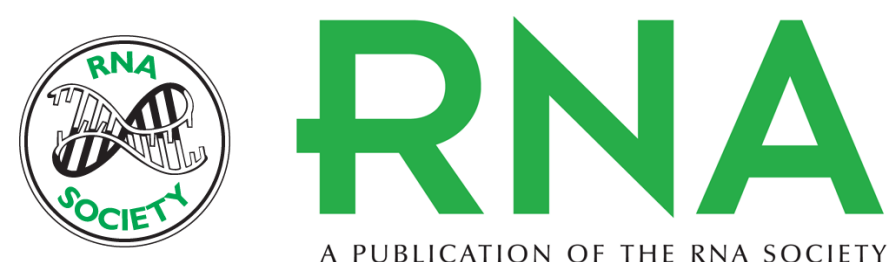

A PUBLICATION OF THE RNA SOCIETY

\section{Seawi-a sea urchin piwi/argonaute family member is a component of MT-RNP complexes}

ALEXIS J. RODRIGUEZ, SUSAN A. SEIPEL, DANIELLE R. HAMILL, et al.

RNA 2005 11: 646-656

References This article cites 49 articles, 20 of which can be accessed free at:

http://rnajournal.cshlp.org/content/11/5/646.full.html\#ref-list-1

\section{License}

Email Alerting Receive free email alerts when new articles cite this article - sign up in the box at the Service top right corner of the article or click here. 